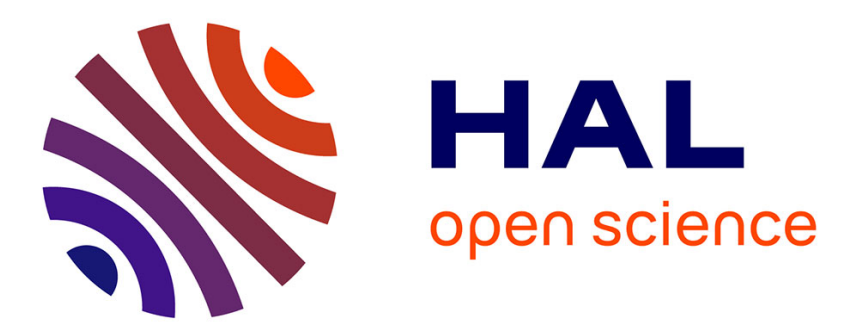

\title{
Reactive hyperaemia in the forearm skin of highly trained windsurfers.
}

E. Heylen, Bernard Simon, F. Guerrero, J.-P. Elkaïm, B. Saïag, J. Mansourati

\section{To cite this version:}

E. Heylen, Bernard Simon, F. Guerrero, J.-P. Elkaïm, B. Saïag, et al.. Reactive hyperaemia in the forearm skin of highly trained windsurfers.. International Journal of Sports Medicine, 2005, 26 (10), pp.822-6. 10.1055/s-2005-837452 . hal-00743424

\section{HAL Id: hal-00743424 \\ https://hal.univ-brest.fr/hal-00743424}

Submitted on 5 Mar 2018

HAL is a multi-disciplinary open access archive for the deposit and dissemination of scientific research documents, whether they are published or not. The documents may come from teaching and research institutions in France or abroad, or from public or private research centers.
L'archive ouverte pluridisciplinaire HAL, est destinée au dépôt et à la diffusion de documents scientifiques de niveau recherche, publiés ou non, émanant des établissements d'enseignement et de recherche français ou étrangers, des laboratoires publics ou privés. 


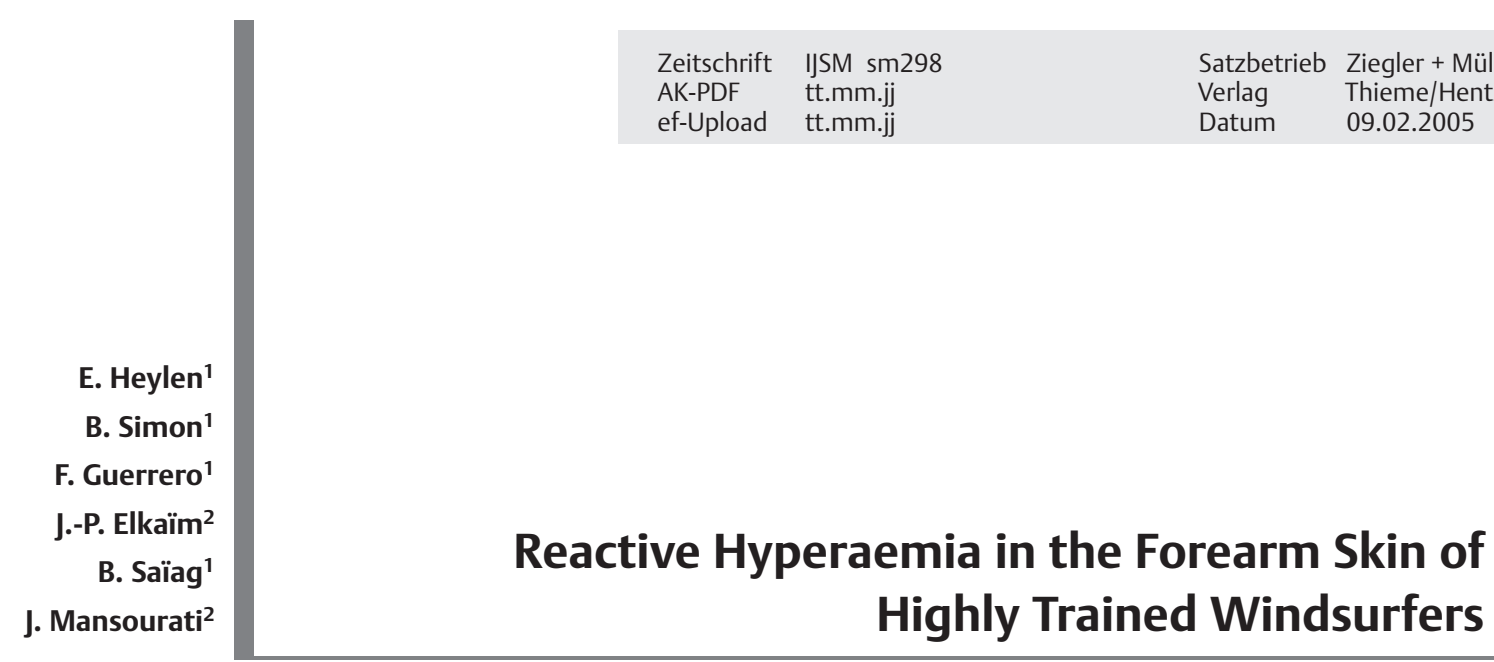

\section{Abstract}

We undertook this study to determine whether long-term high intensity exercise would modify cutaneous endothelial-dependent vasodilation. We compared a group of 9 highly trained windsurfers (mean age: $24.5 \pm 1.6$ years) to a control group of 8 sedentary individuals ( $22.9 \pm 0.4$ years, NS). Laser Doppler was used to measure cutaneous blood flow in the resting state (baseline), during post-occlusive hyperaemia (endothelium-dependent vasodilation), and local heating to $42^{\circ} \mathrm{C}$. Lipid profile was similar in both groups. Resting heart rate was significantly lower in windsurfers. Baseline cutaneous vascular conductance (CVC) values were similar in both groups $(0.059 \pm 0.016$ and $0.051 \pm 0.009)$.
During reactive hyperaemia, normalized peak CVC value was significantly higher in the windsurfers group $(1775.4 \pm 286.9$ and $826.4 \pm 121.7 \%$ baseline CVC; $p=0.01$ ). Normalized peak CVC value in response to local heating $\left(42^{\circ} \mathrm{C}\right)$ was not significantly different between both groups (2359.4 \pm 346.1 and $1467.7 \pm 282.6 \%$ baseline (VC). Endothelium-dependent vasodilation in cutaneous microcirculation is significantly enhanced in the forearm skin of highly trained windsurfers when compared to sedentary controls.

\section{Key words}

Exercise $\cdot$ laser Doppler $\cdot$ endothelium $\cdot$ vasodilation

\section{Introduction}

Exercise training induces adaptation of the cardiovascular system, resulting in improvement of oxygen intake by both cardiac and skeletal muscles $[10,35]$. Adaptation mechanisms include improvement of endothelial function via modifications in synthesis and release of endothelium-derived factors. These beneficial effects have been shown in animal models $[4,7]$ and in human $[13,15,21]$. On the contrary, studies after bed rest or simulated microgravity exposure showed that vasodilator responses were reduced $[5,25]$. Altered response is suggested to be related to several factors in this case: reduction in plasma volume, decreased ability to translocate blood from the splanchnic region to the skin [25], and reduction in local heat-induced nitric oxide (NO) production and/or responsiveness to NO [5].

Increase in forearm blood flow after exercise training suggests that elevated shear stress contributes to endothelial adaptation and cardiovascular protective effects of exercise $[15,20,32]$. Reactive hyperaemia $(\mathrm{RH})$ to an ischemic block is thought to reflect endothelial function and to be mediated mainly by the release of NO and prostacyclin from endothelium $[1,6,8,22,26]$. However, mechanisms that are involved in this response remain controversial as some authors suggest that NO does not play a role in RH in skin $[36,37]$. Previous clinical studies investigated RH by ultrasonography of brachial artery or venous occlusion plethysmogra-

${ }^{1}$ E.A. 3879 Unité de Physiologie Comparée et Intégrative, Groupe Endothélium Vasculaire, Exercice, Nutrition et Santé et G.I.S. Sciences du Mouvement, U.F.R. Sport et Education Physique, Brest, France

${ }^{2}$ Département de Cardiologie, Hôpital de la Cavale Blanche, C.H.U. Brest, France

\section{Correspondence}

E. Heylen · E. A. 3879 Unité de Physiologie Comparée et Intégrative, U.F.R. Sport et Education Physique . 20 avenue Le Gorgeu C.S. 93837 - 29238 Brest Cedex 3 · France · Phone: +33298016260 . Fax: + $33298017946 \cdot$ E-mail: erwan.heylen@univ-brest.fr

Accepted after revision: November 20, 2004 
phy in the forearm $[8,17,34]$. Adaptive changes may be also present in cutaneous vasculature that has the advantage of being easily accessible for monitoring using Laser-Doppler (LD) technique $[18,23]$.

However, effect of exercise has been poorly evaluated with this technique [24]. The purpose of the present study was to determine whether physical conditioning is associated with enhanced endothelium-dependent vasodilation in cutaneous vasculature of healthy men when compared to sedentary controls. LD and $\mathrm{RH}$ were used to evaluate endothelial function in cutaneous microcirculation [2,3]. Local heating to $42^{\circ} \mathrm{C}$ was used as an alternate method to induce vasodilation in our subjects.

\section{Methods}

This study included 9 male windsurfers and a control group of 8 sedentary healthy males. Athletes were training at least 3-4 times per week, each lasting at least $3 \mathrm{~h}$, and were participating in international competitions. They had sailed for $11.7 \pm 1.6$ years and undertook on an average $10.4 \pm 0.7 \mathrm{~h}$ of sailing per week. During the month preceding LD measurements, training encompassed $13.7 \pm 2.2 \mathrm{~h}$ per week.

After written informed consent all subjects undertook a screening program that comprised a medical and training history, baseline blood pressure, anthropometric characteristics (height, weight, maximal forearm girth, and wrist girth), and lipid profile. All subjects were non-smokers, normotensive, and were not on any medication at the time of the study.

All procedures were performed in a quiet temperature-controlled-room at $24.0 \pm 0.3^{\circ} \mathrm{C}$. Subjects were asked to empty their bladder before measurements and to remain in the supine position. LD measurements started at least after 20 min of rest. LD probe (Periflux PF 4001 -2, Perimed, Uppsala, Sweden) was always placed on the ventral site of dominant forearm, $5 \mathrm{~cm}$ below the elbow bend in order to avoid site to site variations $[18,19,29]$. Cutaneous blood flow was measured from a small volume of skin $\left(\sim 1 \mathrm{~mm}^{3}\right)$ using laser beam at $650 \mathrm{~nm}$ wavelengths. To obtain rapid-inflation and deflation during $\mathrm{RH}$, an arm cuff was connected to an automatic device (Hokanson, Model E20, Bellevue, WA, USA) and placed around the upper arm. Blood pressure was measured before and after the protocol. Heart rate was monitored (Polar S610 Finland). Baseline measurements were performed for at least 3-4 min duration.

After baseline measurements, the arm cuff was inflated to $200 \mathrm{~mm} \mathrm{Hg}$ for $5 \mathrm{~min}$ and $\mathrm{RH}$ was recorded after cuff deflation (endothelium-dependent response).

The recovery period was defined until blood flow returned to baseline values. Thereafter, the measure site was warmed to $42{ }^{\circ} \mathrm{C}$ for $5 \mathrm{~min}$ in order to reach a stable plateau of blood flow value using a thermostatically controlled heater of $32 \mathrm{~mm}$ diameter (PF 450 Perimed, Uppsala, Sweden), which could be fixed on the same cutaneous site. The LD probe was placed in the middle of this area.
Zeitschrift IJSM sm298

AK-PDF tt.mm.jj

ef-Upload tt.mm.jj

Satzbetrieb Ziegler + Müller

Verlag Thieme/Hentze

Datum 09.02.2005

All traces (baseline, $\mathrm{RH}$, and local heating) were recorded using Perisoft V.5.10 (Perimed Software). The signal intensity depends on velocity and concentration of moving blood cells in the examined site and gives a semi quantitative assessment of microvascular blood concentration. This latter parameter was chosen according to a previous report suggesting that during the initial phase of $\mathrm{RH}$, the high value of LDF signal is produced by an increasing number of erythrocytes in the vasodilated cross-section than an increase in moving blood cells velocities [16].

Baseline blood flow is the mean value of all readings over a stable 2-min period. Area under the hyperaemic curve is the area from release of ischemia till recovery. Peak flow was defined as the highest recorded blood flow following cuff deflation ( $\mathrm{RH}$ peak) or following local heating ( $\mathrm{T}$ peak). Time to peak ( $\mathrm{s}$ ) is defined as the time to reach $\mathrm{RH}$ peak after cuff deflation. $\mathrm{TR}_{1 / 2}(\mathrm{~s})$ is the time between $\mathrm{RH}$ peak and the fall to $50 \%$ of this value. $\mathrm{T}_{\text {recovery }}$ (s) is the time between deflation and return to baseline value. For data analysis, CVC was indexed as cutaneous blood flow (in arbitrary concentration units) divided by mean arterial blood pressure (in $\mathrm{mm} \mathrm{Hg}$ ) and normalized to baseline values. The arbitrary units correspond to the voltage of the analogue signal of the LD flowmeter with the zero value corresponding to the blood flow value during arterial occlusion. Data were digitised and stored on a computer for analysis. Results are expressed as mean \pm standard error (SE). Values obtained in the two groups were compared using $t$-test. The difference was considered statistically significant if $\mathrm{p}<0.05$.

\section{Results}

Subjects characteristics are summarized in Table 1. Maximal forearm girth was significantly higher in the windsurfers, which was not surprising as it reflects windsurfing effect on forearm musculature and demonstrates the intensity of their physical training. No statistical differences were found in wrist girth, height, and weight. Heart rate was significantly lower in windsurfers. Diastolic blood pressure was similar in the two groups, while systolic and mean blood pressures were significantly higher in the control group. Lipid profile was similar in both groups.

Table 1 Subjects characteristics

\begin{tabular}{lcc}
\hline & Windsurfer $\mathbf{n = 9}$ & Control $\mathbf{n = 8}$ \\
\hline Age (years) & $24.5 \pm 1.6$ & $22.9 \pm 0.4$ \\
\hline Height $(\mathrm{cm})$ & $179.9 \pm 2.2$ & $181.3 \pm 2.0$ \\
\hline Weight $(\mathrm{kg})$ & $75.7 \pm 2.7$ & $72.9 \pm 1.3$ \\
\hline Maximal forearm girth $(\mathrm{cm})$ & $28.8 \pm 0.3$ & $26.8 \pm 0.5^{* *}$ \\
\hline Wrist girth $(\mathrm{cm})$ & $16.9 \pm 0.3$ & $16.6 \pm 0.3$ \\
\hline Systolic blood pressure $(\mathrm{mm} \mathrm{Hg})$ & $120.6 \pm 2.7$ & $130.0 \pm 2.8^{*}$ \\
\hline Diastolic blood pressure $(\mathrm{mm} \mathrm{Hg})$ & $67.5 \pm 2.5$ & $75.0 \pm 3.3$ \\
\hline Mean & $85.0 \pm 2.2$ & $93.2 \pm 2.6^{*}$ \\
\hline Resting heart rate (beats $/ \mathrm{min})$ & $53.8 \pm 2.3$ & $67.0 \pm 3.6^{* *}$ \\
\hline
\end{tabular}

Values are means \pm SE. ${ }^{*} \mathrm{p}<0.05,{ }^{* *} \mathrm{p}<0.01$ 


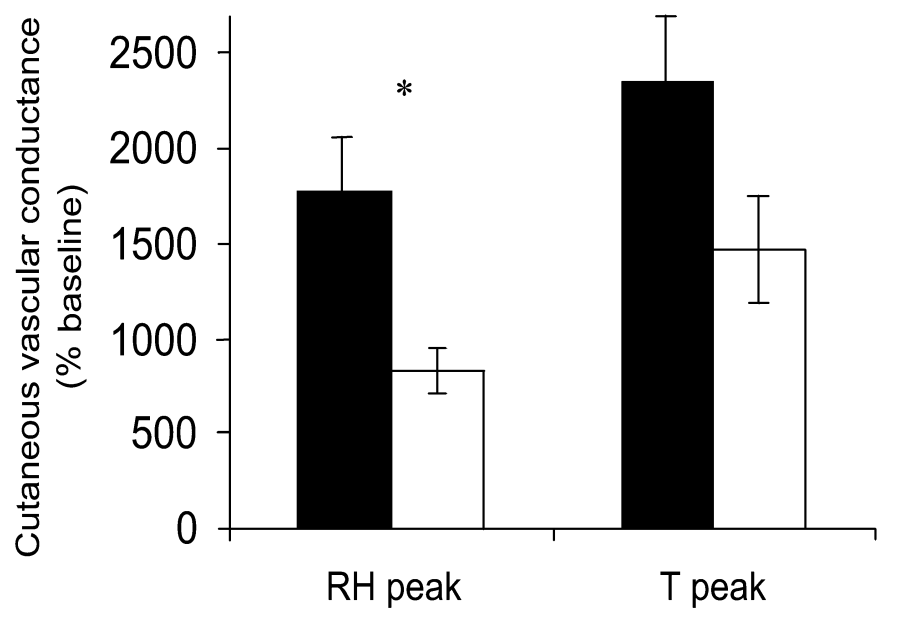

Windsurfers $\quad \square$ Controls

Fig. 1 Effects of training on cutaneous vascular conductance. RH peak $=$ reactive hyperaemia peak and $\mathrm{T}$ peak $=$ local heating peak to $42^{\circ} \mathrm{C} .{ }^{*} \mathrm{p}<0.05$.

Briefly, LDL cholesterol/HDL cholesterol ratio was $1.9 \pm 0.2$ in the windsurfers and $2.1 \pm 0.2$ in controls (NS).

Baseline CVC values in windsurfers was not significantly different than controls $(0.059 \pm 0.016$ and $0.051 \pm 0.009$, NS). Normal-
Zeitschrift IJSM sm298

AK-PDF tt.mm.jj

ef-Upload tt.mm.jj
Satzbetrieb Ziegler + Müller

Verlag Thieme/Hentze

Datum 09.02.2005

ized RH CVC peak in windsurfers was significantly higher than in controls (1775.4 \pm 286.9 and $826.4 \pm 121.7 \%$ baseline CVC; $\mathrm{p}=0.01$ ). Normalized peak CVC value in response to local heating $\left(42^{\circ} \mathrm{C}\right)$ was not significantly different between both groups (2359.4 \pm 346.1 and $1467.7 \pm 282.6 \%$ baseline CVC, NS) (Fig. 1).

Furthermore when we analysed RH traces, we found a significantly higher area under the hyperaemic curve in windsurfers than in controls ( $3675.1 \pm 307.4$ and $1418.1 \pm 256.0$ Concentration Units $\times \mathrm{S}$ respectively; $\mathrm{p}=0.00005) . \mathrm{T}_{\text {recovery }}$ was significantly higher in windsurfers $(144.0 \pm 14.2 \mathrm{~s})$ than in controls $(96.7 \pm 15.6 \mathrm{~s} ; \mathrm{p}=0.04) . \mathrm{TR}_{1 / 2}$ was not different in windsurfers $(20.6 \pm 3.3 \mathrm{~s})$ when compared to controls $(29.5 \pm 10.5 \mathrm{~s}$; NS). Time to peak response was not statistically different in both groups $(23.5 \pm 3.9 \mathrm{~s}$ in windsurfers and $19.8 \pm 2.3 \mathrm{~s}$ in controls; NS) (Fig. 2).

\section{Discussion}

The main result of this study is the beneficial effect of training on endothelial function of cutaneous microcirculation as $\mathrm{RH}$ peak measured by LD in windsurfers forearm skin is significantly higher when compared to sedentary controls. The observed difference in $\mathrm{RH}$ at rest would indicate a true difference in the capacity of endothelial cells to induce vasodilation, probably as a

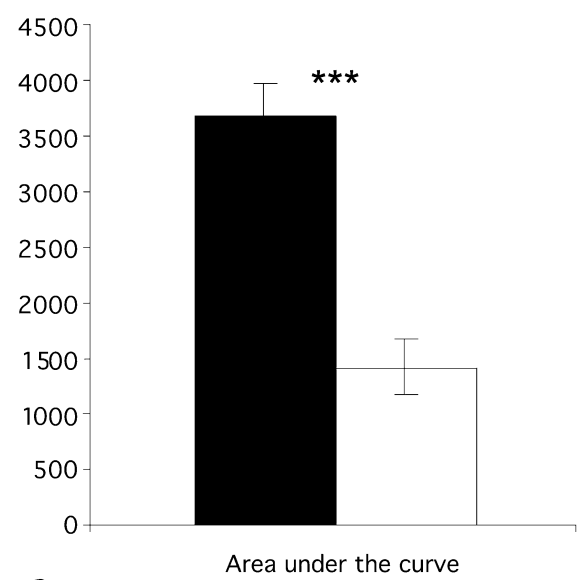

a

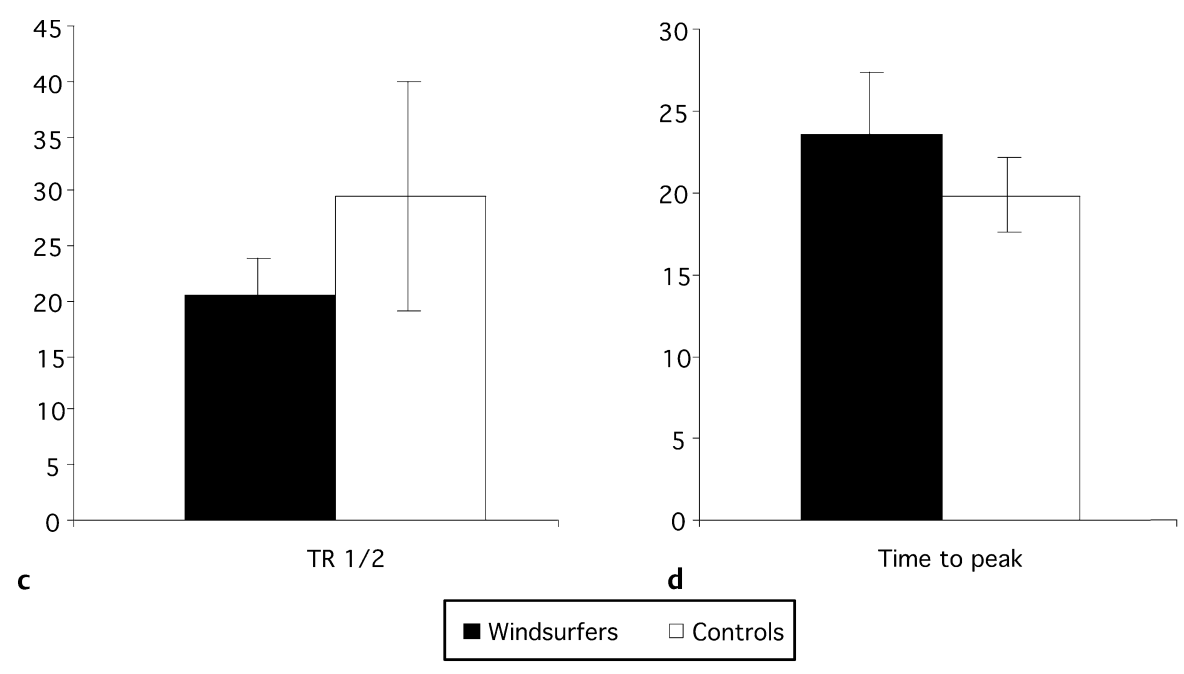

Fig. $\mathbf{2}$ a to $\mathbf{d}$ Effects of training on reactive hyperaemia parameters. After 5 min arterial occlusion. a Area under the curve, $\mathbf{b}$ recovery time, $\boldsymbol{c}$ time between reactive hyperaemia peak and fall to $50 \%$ of this value, d time to peak. ${ }^{*} \mathrm{p}<0.05 ;{ }^{* * *} \mathrm{p}<0.001$.

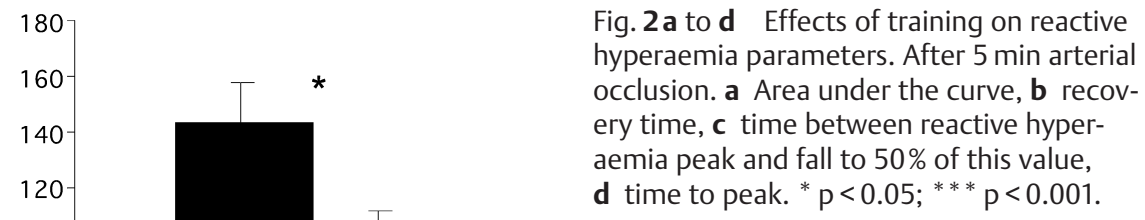


result of repetitive increases in blood flow during training sessions. The other result of the study is the lack of difference in $\mathrm{T}$ peak between both groups. Response to local heating has been demonstrated to be mediated by at least two independent mechanisms: a fast-responding vasodilator system mediated by axon reflexes and a more slowly responding vasodilator system that relies on local production of NO [27]. This may explain the lack of significant effect of training on the response to this provocative test.

These results are in agreement with other studies that showed beneficial effect of exercise on endothelium-dependent vasodilation $[11,14,15,28,31]$. Most of these studies used plethysmography or ultrasound techniques concomitantly to RH. Only one study evaluated this effect on human skin vasculature using acetylcholine iontophoresis and showed enhanced endothelium-dependent vasodilation in athletes (long distance runners) [24]. The main interest of our study is that our technique is simple and does not require any drug application. Although this protocol studied endothelium-dependent vasodilation differently ( $\mathrm{RH}$ instead of acetylcholine iontophoresis), and a different trained population (windsurfers), our results are similar. Therefore beneficial effect on forearm skin is probably not only a regional effect related to the fact that forearms are mainly solicited in windsurfers. Exercise is known to exert a generalized effect on the vasculature by increasing NO activity in other vessels than those that perfuse the actively working muscle $[12,33]$. In a study evaluating fitness-induced improvement of endothelial function by plethysmography and RH, O'Sullivan showed that the magnitude of differences between fit and sedentary individuals was not related to the amount of arm activity [31].

Postischemic RH results mainly from the release of endotheliumderived relaxing factors and from the stimulation of adenin-triphosphate-sensitive potassium channels $[1,6,8,22,26]$. NO, the most important endothelium-derived relaxing factor, contributes to all phases of RH including peak flow in normal human vasculature $[6,17,26,34]$. In contrast, some authors found that dermal vasodilation in response to acetylcholine is mediated predominantly by prostanoids rather than NO $[3,30]$. Furthermore, it was suggested that NO does not directly mediate $\mathrm{RH}$ in the skin by other authors $[36,37]$. Prostaglandins appeared also to be important factors during RH in studies using plethysmography while NO contribution seemed to be modest [8]. Although the exact mechanisms involved in $\mathrm{RH}$ are not completely understood, this provocative test associated to LD is considered a suitable method to assess endothelial function in the skin microcirculation. The aim of our study was not to evaluate each factor contribution in this response.

We also evaluated the effect of exercise on other parameters. Most of them are related to response duration. Time to peak during RH was not significantly different between windsurfers and controls. This result is similar to that found in rock climbers using plethysmography [9]. The second parameter, $\mathrm{TR}_{1 / 2}$, was not different between both groups. Our values are similar to those reported by O'Sullivan [31]. Therefore these two parameters do not seem to be interesting to follow exercise effect on endothelium-dependent vasodilation.
However, two other parameters were found to be significantly different between our groups: $\mathrm{T}_{\text {recovery }}$ and the area under the hyperaemic curve. These parameters are significantly higher in windsurfers particularly the area under the hyperaemic curve. This parameter was previously showed to be reduced by infusion of L-NMMA (a specific NO synthase inhibitor) [17,26,34]. However, unlike our technique which evaluates skin microcirculation, these studies used plethysmography which evaluates forearm blood flow including skin and muscle. As NO synthase was suggested not to play a major role in RH in skin, comparisons should be cautious. Are these two parameters $\left(\mathrm{T}_{\text {recovery }}\right.$ and the area under the hyperaemic curve) more specific of NO production during RH? Further studies are necessary to prove this assumption.

\section{Study limitations}

We included a small number of subjects. However, our 2 groups were homogenous with regard to their arterial risk factors and the relevant difference between them was exercise.

Resting heart rate and systolic blood pressure were significantly lower in windsurfers than in controls which may have influenced the results. However, although these two parameters were lower in the windsurfers, RH peak was significantly higher in this group which emphasizes our results.

Although not the optimal standardization method, peak ( $\mathrm{RH}$ and local heating) CVC values were normalized to baseline values. Standardization would have been best accomplished by infusion of sodium nitroprusside or hyperthermia to cause maximal vasodilation. As we preferred the use of a simple protocol, maximal dilation was not available in this study.

In conclusion, physical conditioning results in enhanced endothelium-dependent vasodilation in the cutaneous microcirculation, as demonstrated by the higher $\mathrm{RH}$ peak in windsurfers than in controls. On the contrary, it does not induce any significant effect on response to local heating $\left(42^{\circ} \mathrm{C}\right)$. LD and $\mathrm{RH}$ seem to be an interesting tool to follow training effect on endothelial function in skin microcirculation.

\section{References}

${ }^{1}$ Banitt PF, Smits P, Williams SB, Ganz P, Creager MA. Activation of ATPsensitive potassium channels contributes to reactive hyperemia in humans. Am J Physiol 1996; 271: 1594-1598

2 Beinder E, Schlembach D. Skin flux during reactive hyperemia and local hyperthermia in patients with preeclampsia. Obstet Gynecol 2001; 98: $313-318$

3 Binggeli C, Spieker LE, Corti R, Sudano I, Stojanovic V, Hayoz D, Luscher TF, Noll G. Statins enhance postischemic hyperemia in the skin circulation of hypercholesterolemic patients: a monitoring test of endothelial dysfunction for clinical practice? J Am Coll Cardiol 2003; 42: $71-77$

${ }^{4}$ Chen HI, Li HT. Physical conditioning can modulate endothelium-dependent vasorelaxation in rabbits. Arterioscler Thromb 1993; 13: $852-856$

${ }^{5}$ Crandall CG, Shibasaki M, Wilson TE, Cui J, Levine BD. Prolonged headdown tilt exposure reduces maximal cutaneous vasodilator and sweating capacity in humans. J Appl Physiol 2003; 94: 2330-2336

${ }^{6}$ Dakak N, Husain S, Mulcahy D, Andrews NP, Panza JA, Waclawiw M, Schenke W, Quyyumi AA. Contribution of nitric oxide to reactive hy- 
peremia: impact of endothelial dysfunction. Hypertension 1998; 32: $9-15$

7 Delp MD, McAllister RM, Laughlin MH. Exercise training alters endothelium-dependent vasoreactivity of rat abdominal aorta. J Appl Physiol 1993; 75: 1354-1363

${ }^{8}$ Engelke KA, Halliwill JR, Proctor DN, Dietz NM, Joyner MJ. Contribution of nitric oxide and prostaglandins to reactive hyperemia in human forearm. J Appl Physiol 1996; 81: 1807-1814

${ }^{9}$ Ferguson RA, Brown MD. Arterial blood pressure and forearm vascular conductance responses to sustained and rhythmic isometric exercise and arterial occlusion in trained rock climbers and untrained sedentary subjects. Eur J Appl Physiol 1997; 76: 174-180

${ }^{10}$ Fritzsche RG, Coyle EF. Cutaneous blood flow during exercise is higher in endurance-trained humans. J Appl Physiol 2000; 88: 738 - 744

${ }^{11}$ Goto C, Higashi Y, Kimura M, Noma K, Hara K, Nakagawa K, Kawamura M, Chayama K, Yoshizumi M, Nara I. Effect of different intensities of exercise on endothelium-dependent vasodilation in humans: role of endothelium-dependent nitric oxide and oxidative stress. Circulation 2003; 108: 530-535

12 Green D, Cheetham C, Mavaddat L, Watts K, Best M, Taylor R, O'Driscoll G. Effect of lower limb exercise on forearm vascular function: contribution of nitric oxide. Am J Physiol 2002; 283: 899-907

${ }^{13}$ Green DJ, Fowler DT, O’Driscoll JG, Blanksby BA, Taylor RR. Endothelium-derived nitric oxide activity in forearm vessels of tennis players. J Appl Physiol 1996; 81: 943 - 948

${ }^{14}$ Hambrecht R, Fiehn E, Weigl C, Gielen S, Hamann C, Kaiser R, Yu J, Adams V, Niebauer J, Schuler G. Regular physical exercise corrects endothelial dysfunction and improves exercise capacity in patients with chronic heart failure. Circulation 1998; 98: 2709-2715

${ }^{15}$ Higashi Y, Sasaki S, Kurisu S, Yoshimizu A, Sasaki N, Matsuura H, Kajiyama G, Oshima T. Regular aerobic exercise augments endotheliumdependent vascular relaxation in normotensive as well as hypertensive subjects: role of endothelium-derived nitric oxide. Circulation 1999; 100: $1194-202$

${ }^{16}$ Humeau A, Saumet JL, L'Huillier JP. Simplified model of laser Doppler signals during reactive hyperaemia. Med Biol Eng Comput 2000; 38: $80-87$

${ }^{17}$ Joannides R, Haefeli WE, Linder L, Richard V, Bakkali EH, Thuillez C. Luscher TF. Nitric oxide is responsible for flow-dependent dilatation of human peripheral conduit arteries in vivo. Circulation 1995; 91 : $1314-1319$

${ }^{18}$ Johnson JM, Taylor WF, Shepherd AP, Park MK. Laser-Doppler measurement of skin blood flow: comparison with plethysmography. J Appl Physiol 1984; 56: 798 - 803

${ }^{19}$ Kastrup J, Bulow J, Lassen NA. Vasomotion in human skin before and after local heating recorded with laser Doppler flowmetry. A method for induction of vasomotion. Int J Microcirc Clin Exp 1989; 8: 205 215

${ }^{20}$ Kingwell BA. Nitric oxide-mediated metabolic regulation during exercise: effects of training in health and cardiovascular disease. Faseb J 2000; $14: 1685-1696$
Zeitschrift IJSM sm298

AK-PDF tt.mm.jj

Satzbetrieb Ziegler + Müller

ef-Upload tt.mm.jj

Verlag Thieme/Hentze 09.02.2005

${ }^{21}$ Kingwell BA, Sherrard B, Jennings GL, Dart AM. Four weeks of cycle training increases basal production of nitric oxide from the forearm. Am J Physiol 1997; 272: 1070-1077

22 Koller A, Kaley G. Role of endothelium in reactive dilation of skeletal muscle arterioles. Am J Physiol 1990; 259: 1313 - 1316

23 Kubli S, Waeber B, Dalle-Ave A, Feihl F. Reproducibility of laser Doppler imaging of skin blood flow as a tool to assess endothelial function. J Cardiovasc Pharmacol 2000; 36: 640-648

${ }^{24}$ Kvernmo HD, Stefanovska A, Kirkeboen KA, Osterud B, Kvernebo K. Enhanced endothelium-dependent vasodilatation in human skin vasculature induced by physical conditioning. Eur J Appl Physiol 1998; 79: $30-36$

25 Lee SM, Williams WJ, Schneider SM. Role of skin blood flow and sweating rate in exercise thermoregulation after bed rest. J Appl Physiol 2002; 92: 2026-2034

${ }^{26}$ Meredith IT, Currie KE, Anderson TJ, Roddy MA, Ganz P, Creager MA. Postischemic vasodilation in human forearm is dependent on endothelium-derived nitric oxide. Am J Physiol 1996; 270: 1435-1440

27 Minson CT, Berry LT, Joyner MJ. Nitric oxide and neurally mediated regulation of skin blood flow during local heating. J Appl Physiol 2001; 91: 1619-1626

28 Niebauer J, Cooke JP. Cardiovascular effects of exercise: role of endothelial shear stress. J Am Coll Cardiol 1996; 28: 1652 - 1660

29 Ninet J, Fronek A. Cutaneous postocclusive reactive hyperemia monitored by laser doppler flux metering and skin temperature. Microvasc Res 1985; 30: 125-132

30 Noon JP, Walker BR, Hand MF, Webb DJ. Studies with iontophoretic administration of drugs to human dermal vessels in vivo: cholinergic vasodilatation is mediated by dilator prostanoids rather than nitric oxide. Br J Clin Pharmacol 1998; 45: 545-550

31 O'Sullivan SE. The effects of exercise training on markers of endothelial function in young healthy men. Int J Sports Med 2003; 24: 404 409

32 Rinder MR, Spina RJ, Ehsani AA. Enhanced endothelium-dependent vasodilation in older endurance-trained men. J Appl Physiol 2000; 88: $761-766$

33 Silber D, McLaughlin D, Sinoway L. Leg exercise conditioning increases peak forearm blood flow. J Appl Physiol 1991; 71: 1568 - 1573

34 Tagawa T, Imaizumi T, Endo T, Shiramoto M, Harasawa Y, Takeshita A. Role of nitric oxide in reactive hyperemia in human forearm vessels. Circulation 1994; 90: 2285-2290

35 Thomas CM, Pierzga JM, Kenney WL. Aerobic training and cutaneous vasodilation in young and older men. J Appl Physiol 1999; 86: 1676 1686

36 Wong BJ, Wilkins BW, Holowatz LA, Minson CT. Nitric oxide synthase inhibition does not alter the reactive hyperemic response in the cutaneous circulation. J Appl Physiol 2003; 95: 504-510

37 Zao JL, Pergola PE, Roman LJ, Kellogg DL Jr. Bioactive nitric oxide concentration does not increase during reactive hyperemia in human skin. J Appl Physiol 2004; 96: 628-632 